\title{
DFT STUDY ON THE MECHANISM OF THE ADDITION REACTION BETWEEN CARBENE AND GLYCINE
}

\author{
XIAOJUN TAN ${ }^{* a}$, WEIHUA WANG ${ }^{b}$, PING LI*, ${ }^{*}$, INSONG GU ${ }^{a}$, GUORONG WANG ${ }^{a}$, \\ DANGSHENG WANG ${ }^{c}, T A O L I^{c}$ \\ ( ${ }^{a}$ College of Medical and Life Science, University of Jinan, Jinan, Shandong, 250022, People's Republic of China) \\ ( ${ }^{b}$ College of Chemistry Science, Qufu Normal University, Qufu, Shandong, 273165, People's Republic of China) \\ ( College of Chemistry and Chemical Engineering, University of Jinan, Jinan, Shandong, 250022, People's Republic of China) \\ (Received: March 26, 2010 - Accepted: March 17, 2011)
}

\begin{abstract}
The mechanism of addition reaction between the singlet carbene and glycine has been investigated at the B3LYP/6-311+G* level of theory, including geometry optimization and vibrational analysis for the involved stationary points on the potential energy surface. Computational results suggest that there are two reaction pathways (1) and (2) during the addition process. In the pathway (1), carbene attacks the $\mathrm{C}=\mathrm{O}$ bond from the $\mathrm{H}^{1} \mathrm{C}^{1} \mathrm{C}^{2}$ side of glycine to form an intermediate (IM1), which is a barrier-free exothermic reaction. Then, IM1 isomerizes to a product (Pro1) via a transition state (TS1) with a potential barrier of $25.7 \mathrm{~kJ} / \mathrm{mol}$. Similarly, in the pathway (2), carbene attacks the $\mathrm{C}=\mathrm{O}$ bond from the $\mathrm{H}^{2} \mathrm{C}^{1} \mathrm{C}^{2}$ side of glycine to form an intermediate IM2. Subsequently, IM2 isomerizes to Pro2 via TS2, where the Pro2 and Pro1 are enantiomers actually. The calculated potential barrier of $51.3 \mathrm{~kJ} / \mathrm{mol}$ is higher than that of the pathway (1). Correspondingly, the reaction energy for the both pathways is $-258.5 \mathrm{~kJ} / \mathrm{mol}$. Additionally, the atoms in molecules (AIM) theory has also been performed to characterize the bonding interaction and structural features for the addition reaction.
\end{abstract}

Key words: Carbene, Glycine, Addition reaction, Density functional theory (DFT).

\section{INTRODUCTION}

Carbene can be defined as a divalent carbon intermediate, where the carbene carbon is linked to two adjacent groups by covalent bonds and possesses two nonbonding electrons ${ }^{1}$. As well known, carbene plays an important role in organic chemistry, especially for the addition reaction between carbene and $\mathrm{C}=\mathrm{O}$ double bond ${ }^{2-7}$. Therefore, much attention has been paid on them not only from applied but also theoretical chemists. For example, they can provide simple and direct synthesis for small-ring, highly strained compounds, as well as those that are hard to synthesize through conventional ways ${ }^{8}$. At present, as an important catalyzer, metal-carbene complexes are applied widely in the organic synthesis $^{9-11}$. Lu et al. reported reaction between carbene or substituted carbene and some small molecules using theoretical calculation ${ }^{12-14}$. Apeloig et al. extensively studied the mechanisms and stereoselectivity of carbene addition to olefin using experimental as well as theoretical methods ${ }^{15,16}$. On the other hand, some extrinsic substance can produce carbene in the human body. For example, carbon tetrachloride $\left(\mathrm{CCl}_{4}\right)$ is a hepatotoxic molecule and a twostep reduction of it would liberate a chloride ion to yield the highly reactive dichlorocarbene. ${ }^{17}$ Dacarbazine (DTIC) is clinically effective in the treatment of several malignant disorders, including metastatic malignant melanoma, melanoma, Hodgkin's disease, and soft tissue sarcomas, in combination with other anticancer drugs ${ }^{18}$. Photoactivated DTIC generates the carbene and aryl radicals, which may induce DNA adduct, resulting in the photogenotoxicity ${ }^{19}$. As the simplest amino acid, glycine plays central roles both as building blocks of proteins and as intermediates in metabolism. Due to the existence of the carboxyl group in glycine, it is probable that the active carbene can react with the glycine. To our best knowledge, this kind of reaction has not been reported so far. Therefore, it is necessary to study the reaction between carbene and glycine to further understand the potential role of carbene in the life fields.

In the present study, the reaction between carbene and glycine has been systematically investigated employing the B3LYP/6-311+G* level of theory. The possible intermediates (IM), transition states (TS), and products (Pro) have been located on the potential energy surface. The possible reaction mechanisms have been proposed. Hopefully, the present results would be helpful to better understand the potential reaction between carbene and life molecules.

\section{Calculation method}

The density functional theory (DFT ${ }^{20,21}$ ) B3LYP method (Becke's threeparameter hybrid function ${ }^{22}$ with the non-local correlation of Lee-Yang-Parr ${ }^{23}$ ) combined with the $6-311+\mathrm{G}^{*}$ basis set are employed to locate all the stationary points along the reaction pathways. Frequency analyses have also been carried out to confirm the nature of the minima and transition states. Moreover, intrinsic reaction coordinate (IRC) calculations have also been performed to further validate the calculated transition states connecting the reactants and products. Additionally, relevant energy quantities, such as reaction energies and barrier energies, have been corrected with zero-point vibrational energy (ZPVE) corrections.

To characterize the structural and bonding features, the atoms in molecules (AIM) theory ${ }^{24}$ has been performed on the basis of the calculated geometries. According to the AIM theory, the existence of a bond is indicated by the presence of a so-called bond critical point (BCP). Similarly, the ring structures are characterized by the existence of a ring critical point (RCP). Additionally, the nature of the chemical bond can be assessed from the calculated Laplacian of electron density at the critical point.

All the calculations have been performed using Gaussian 98 program $^{25}$.

\section{RESULTS AND DISCUSSION}

It is reported that there are 13 stable conformers for glycine in the gas phase. ${ }^{26}$ As displayed in Figure 1, for the most stable conformer, the main skeleton of it, such as $\mathrm{N}, \mathrm{C}^{1}, \mathrm{C}^{2}, \mathrm{O}^{1}$, and $\mathrm{O}^{2}$ atoms, are in the same plane approximately. Obviously, the weak intramolecular $\mathrm{H}$-bonds exist between $\mathrm{O}^{1}$ and $\mathrm{H}^{3}, \mathrm{H}^{4}$, and $\mathrm{H}^{5}$. For the sake of simplicity, the most stable glycine has been discussed in the following study.

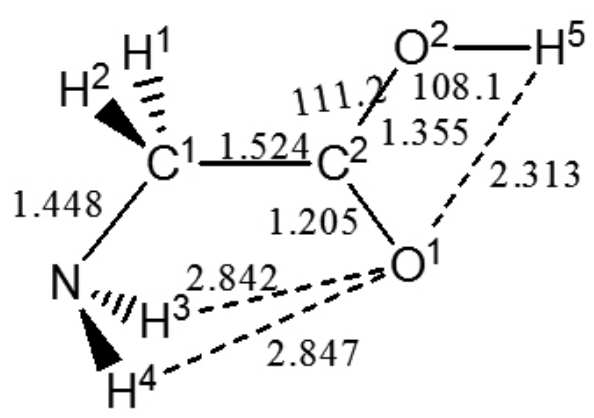

Figure 1. The most stable glycine optimized at the B3LYP/6-311+G* level of theory, where the bond length and bond angle are in angstrom and degree, respectively. 
There are two possible pathways for the addition reaction between carbene and glycine as follows:

$$
\mathrm{H}_{2} \mathrm{C}:+ \text { glycine } \rightarrow \mathrm{IM} 1 \rightarrow \mathrm{TS} 1 \rightarrow \text { Pro1 }
$$$$
\mathrm{H}_{2} \mathrm{C}:+ \text { glycine } \rightarrow \mathrm{IM} 2 \rightarrow \mathrm{TS} 2 \rightarrow \mathrm{Pro} 2
$$

Here, both pathways (1) and (2) are similar to each other. Namely, in the pathway (1), carbene attacks the $\mathrm{C}=\mathrm{O}$ bond from the $\mathrm{H}^{1} \mathrm{C}^{1} \mathrm{C}^{2}$ side of glycine to form an intermediate (IM1) before isomerizing to a product (Pro1) via a transition state (TS1). Certainly, in the pathway (2), carbene can also attack the $\mathrm{C}=\mathrm{O}$ bond from the $\mathrm{H}^{2} \mathrm{C}^{1} \mathrm{C}^{2}$ side of glycine to form an intermediate (IM2), which isomerizes to Pro2 via TS2.

\subsection{Reaction pathway (1) between carbene and glycine}

When carbene approaches glycine from the $\mathrm{H}^{1} \mathrm{C}^{1} \mathrm{C}^{2}$ side, it can form an intermediate (IM1) with the $\mathrm{C}^{2}=\mathrm{O}^{1}$ double bond of glycine, which is a barrierfree process. The geometrical parameters for the intermediate (IM1), transition state (TS1), and product (Pro1) in the pathway (1) are given in Figure 2. Correspondingly, the relevant energy quantities have been summarized in Table 1 . The unique imaginary frequency of the transition state TS1 is $288.79 \mathrm{i}$ $\mathrm{cm}^{-1}$ and the transition state can therefore be affirmed as real. Moreover, the calculated TS1 connecting IM1 and Pro1 can be further confirmed by the IRC calculations.

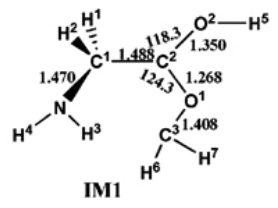

$\angle O^{\prime} C^{\prime} C^{2} O^{2}=173.4$ $\angle \mathrm{C}^{3} \mathrm{C}^{1} \mathrm{C}^{2} \mathrm{O}^{1}=-6.6$ $\angle \mathrm{NC}^{1} \mathrm{C}^{2} \mathrm{O}^{2}=-109.7$

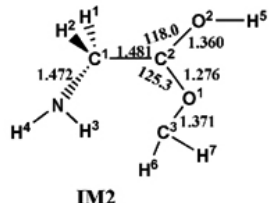

IM2

$\angle O^{1} C^{1} C^{2} O^{2}=176.1$

$\angle \mathrm{C}^{3} \mathrm{C}^{1} \mathrm{C}^{2} \mathrm{O}^{1}=-3.3$

$\angle \mathrm{NC}^{1} \mathrm{C}^{2} \mathrm{O}^{2}=102.6$

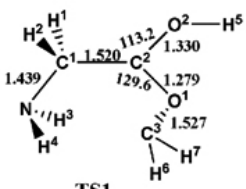

TS

$\angle O^{1} C^{1} C^{2} O^{2}=-166.5$ $\angle \mathrm{C}^{3} \mathrm{C}^{1} \mathrm{C}^{2} \mathrm{O}^{1}=-32.8$ $\angle \mathrm{NC}^{1} \mathrm{C}^{2} \mathrm{O}^{2}=-159.2$

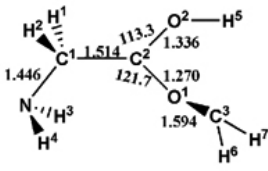

TS2

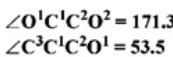

$\angle \mathrm{C}^{3} \mathrm{C}^{1} \mathrm{C}^{2} \mathrm{O}^{1}=53.5$ $\angle \mathrm{NC}^{1} \mathrm{C}^{2} \mathrm{O}^{2}=171.3$

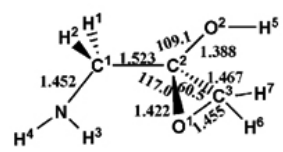

Pro1

$\angle O^{1} C^{1} C^{2} O^{2}=-134.0$ $\angle \mathrm{C}^{3} \mathrm{C}^{1} \mathrm{C}^{2} \mathrm{O}^{1}=154.8$ $\angle \mathrm{NC}^{1} \mathrm{C}^{2} \mathrm{O}^{2}=-177.8$

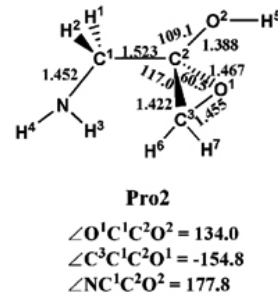

Figure 2. Optimized structures of intermediates(IM), TSs, and products(Pro), where the bond length and bond angle are in angstrom and degree, respectively.

Obviously, pathway (1) consists of two steps. Namely, an intermediate IM1 has been spontaneously formed firstly, which is stabilized by about 67.4 $\mathrm{kJ} / \mathrm{mol}$ relative to the reactants. Then, IM1 isomerizes to product Prol with a barrier of $25.7 \mathrm{~kJ} / \mathrm{mol}$. The overall reaction energy is about $-258.5 \mathrm{~kJ} / \mathrm{mol}$, implying that the pathway (1) is an exothermic process.

Table 1: The electronic structure energies (ESE), zero-point energies (EZP), total energies (ET) and relative energies (ER) for the species of the addition reaction between carbene and glycine at the B3LYP/6-311+G* level of

\begin{tabular}{|c|c|c|c|c|}
\hline Species & $\mathrm{E}_{\mathrm{SE}} /$ a.u. & $\mathrm{E}_{\mathrm{ZP}} /$ a.u. & $\mathrm{E}_{\mathrm{T}}{ }^{\mathrm{a}} / \mathrm{a} . \mathrm{u}$. & $\begin{array}{c}\mathrm{E}_{\mathrm{R}} /(\mathrm{kJ} / \\
\mathrm{mol})\end{array}$ \\
\hline $\begin{array}{c}\mathrm{H}_{2} \mathrm{C}:+ \\
\text { glycine }\end{array}$ & -323.6575772 & 0.096429 & -323.561148 & 0.0 \\
\hline $\mathrm{IM} 1$ & -323.6916628 & 0.104836 & -323.586827 & -67.4 \\
\hline TS1 & -323.6817615 & 0.104717 & -323.577045 & -41.7 \\
\hline Pro1 & -323.7671853 & 0.107548 & -323.659637 & -258.5 \\
\hline $\mathrm{IM} 2$ & -323.6883424 & 0.104215 & -323.584127 & -60.3 \\
\hline TS2 & -323.6673902 & 0.102820 & -323.564571 & -9.0 \\
\hline Pro2 & -323.7671853 & 0.107550 & -323.659635 & -258.5 \\
\hline${ }^{\mathrm{a}} \mathrm{E}_{\mathrm{T}}=\mathrm{E}_{\mathrm{SE}}+\mathrm{E}_{\mathrm{ZP}}$ & & & \\
\hline
\end{tabular}

Compared with the isolated glycine, the double bond character of the $\mathrm{C}^{2}=\mathrm{O}^{1}$ in IM1 has been weakened. For example, the bond length of it has been prolonged by $0.063 \AA$ than that in isolated glycine. The corresponding electron densities at the BCP has been decreased by about 0.0772 . At the same time, the dihedral angle of the $\mathrm{O}^{1} \mathrm{C}^{1} \mathrm{C}^{2} \mathrm{O}^{2}$ in IM1 has been changed to $173.4^{\circ}$.

As for transition state TS1, the distance of the $\mathrm{C}^{2}-\mathrm{C}^{3}$ has been shortened by about $0.213 \AA$ to $2.202 \AA$ compared with that of the IM1 despite of the nonexistence of the corresponding BCP using AIM theory. At the same time, the distance of $\mathrm{C}^{2}-\mathrm{O}^{1}$ has been elongated to $1.279 \AA$, which is in the intermediate between the normal $\mathrm{C}-\mathrm{C}$ single bond and $\mathrm{C}=\mathrm{C}$ double bond. Thus, in the TS1, the new $\mathrm{C}^{2}-\mathrm{C}^{3}$ bond is to be formed and the $\mathrm{C}^{2}-\mathrm{O}^{1}$ bond is to be broken simultaneously. On the other hand, the dihedral angle of $\mathrm{C}^{3} \mathrm{C}^{1} \mathrm{C}^{2} \mathrm{O}^{2}$ in TS1 has been changed to $-32.8^{\circ}$, which also suggest that it is impossible for $\mathrm{C}^{2}$ atom to maintain $s p^{2}$ hybridization state.

Compared with TS1, the distance of $\mathrm{C}^{2}-\mathrm{C}^{3}$ in product Prol has been further shortened to $1.467 \AA$, which denote the formation of the $\mathrm{C}^{2}-\mathrm{C}^{3}$ bond. At the same time, the distance of the $\mathrm{C}^{2}-\mathrm{O}^{1}$ has been elongated to $1.422 \AA$, suggesting that the initial double bond between $\mathrm{C}^{2}$ and $\mathrm{O}^{1}$ has been transformed to single bond. Additionally, as shown in Table 2, there is a RCP involving the $\mathrm{O}^{1}, \mathrm{C}^{2}$, and $\mathrm{C}^{3}$ atom, suggesting the formation of a three-membered ring structure among the $\mathrm{O}^{1}, \mathrm{C}^{2}$, and $\mathrm{C}^{3}$ atom.

As shown in Figure 3, the mechanism of the reaction (1) could be explained with the knowledge of the frontier molecular orbital. The combination of the unoccupied $2 p$ orbital of the $\mathrm{C}^{3}$ atom in carbene with the $\pi$ orbital of $\mathrm{C}^{2}-\mathrm{O}^{1}$ in glycine gives a $\pi \rightarrow p$ donor-acceptor bond, resulting in the formation of the intermediate IM1 characterized by a three-membered ring structure when carbene initially interacts with glycine. We have done detailed potential energy surface scan for the formation of IM1. Computational results show that the formation of IM1 is a barrier-free exothermic reaction, which is probably due to the strong bonding effect of the $2 p$ unoccupied orbital of $\mathrm{C}^{3}$ atom of carbene with the $\pi$-bonded electron cloud of $\mathrm{C}^{2}-\mathrm{O}^{1}$ of glycine. With the reaction going on, carbene will rotate clockwise in the plane of $\mathrm{C}^{3} \mathrm{C}^{2} \mathrm{O}^{1}$, and then the lone electron pair of carbene can enter the $\pi^{*}$ orbital of $\mathrm{C}^{2}-\mathrm{O}^{1}$ of glycine. Accordingly, the addition reaction completes finally.

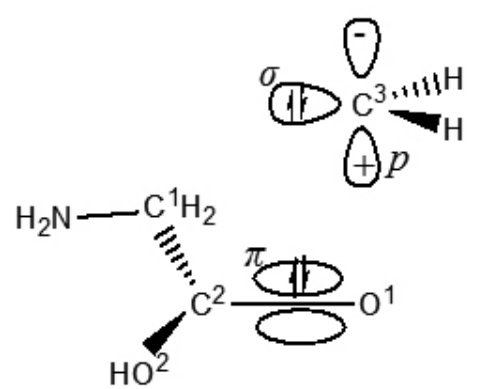

Figure 3. MO symmetry-adaption of carbene and the $\mathrm{C}=\mathrm{O}$ of glycine. 
Table 2: Charge Density $\rho$ and its Laplacian $\nabla 2 \rho$ as well as its eigenvalues at the bond critical point (BCP) and ring critical point (RCP) for the addition reaction between carbene and glycine (pathway (1)) calculated at the B3LYP/6-311+G* level of theory.

\begin{tabular}{|c|c|c|c|c|c|c|}
\hline Conformer & Atom Pair & $\rho$ & $\lambda_{1}$ & $\lambda_{2}$ & $\lambda_{3}$ & $\nabla^{2} \rho$ \\
\hline \multirow[t]{2}{*}{ IM1 } & $\mathrm{O}^{1}-\mathrm{C}^{3}$ & 0.2171 & -0.3102 & -0.1779 & 0.8120 & 0.3239 \\
\hline & $\mathrm{C}^{2}-\mathrm{O}^{1}$ & 0.3416 & -0.8552 & -0.6359 & 1.6576 & 0.1665 \\
\hline \multirow[t]{2}{*}{ TS1 } & $\mathrm{O}^{1}-\mathrm{C}^{3}$ & 0.1729 & -0.1996 & -0.1387 & 0.3376 & -0.0007 \\
\hline & $\mathrm{C}^{2}-\mathrm{O}^{1}$ & 0.3598 & -0.9171 & -0.8164 & 1.2604 & -0.4731 \\
\hline \multirow[t]{4}{*}{ Pro1 } & $\mathrm{O}^{1}-\mathrm{C}^{3}$ & 0.2347 & -0.4253 & -0.2442 & 0.3872 & -0.2823 \\
\hline & $\mathrm{C}^{2}-\mathrm{O}^{1}$ & 0.2589 & -0.5100 & -0.3342 & 0.4209 & -0.4233 \\
\hline & $\mathrm{C}^{2}-\mathrm{C}^{3}$ & 0.2527 & -0.5195 & -0.4330 & 0.3666 & -0.5859 \\
\hline & $\mathrm{O}^{1}-\mathrm{C}^{2}-\mathrm{C}^{3}$ & 0.2062 & -0.3803 & 0.2284 & 0.5160 & 0.3641 \\
\hline
\end{tabular}

As displayed in Figure 3, due to the existence of the lone electrons in carbene fragment, IM1 possesses high energy relative to the corresponding product. Therefore, the system reduces its own energy by increasing the dihedral angles $<\mathrm{C}^{3} \mathrm{C}^{1} \mathrm{C}^{2} \mathrm{O}^{1}$ (IM1: $-1.7^{\circ}$; TS1: $-32.8^{\circ}$; Pro1: $154.8^{\circ}$ ), resulting in the formation of the more stable product Pro1 via TS1. As shown in Table 2, there is no BCP between $\mathrm{C}^{2}$ and $\mathrm{C}^{3}$ in IM1 and TS1. However, a BCP of this bond exists in Pro1 within the framework of the AIM theory. Moreover, from the calculated negative Laplacian at the $\mathrm{BCP}$, the $\mathrm{C}^{2}-\mathrm{C}^{3}$ bond in Prol should be covalent in nature.

\subsection{Reaction pathway (2) between carbene and glycine}

As displayed in Figure 2, the pathway (2) is similar to the reaction pathway (1). Thus, the analyses above for the pathway (1) are also true here. Namely, in the pathway (2), carbene attacks the $\mathrm{C}=\mathrm{O}$ bond from the $\mathrm{H}^{2} \mathrm{C}^{1} \mathrm{C}^{2}$ side of glycine to form an intermediate IM2, which isomerizes to Pro2 via TS2. Here, it should be noted that Pro2 and Pro1 are enantiomers actually. The selected geometrical parameters for the intermediate (IM2), transition state (TS2), and product (Pro2) are given in Figure 2. The unique imaginary frequency of the transition state TS2 is $299.38 \mathrm{i} \mathrm{cm}^{-1}$, which has been further confirmed by the IRC calculations.

Based on Table 1, IM2 is less stable than IM1 by about $7.1 \mathrm{~kJ} / \mathrm{mol}$, suggesting that IM1 is favorable to be generated from reactants thermodynamically. Moreover, the barrier in pathway (1) $(25.7 \mathrm{~kJ} / \mathrm{mol})$ is lower by about $25.6 \mathrm{~kJ} /$ mol than that in pathway (2). Thus, the pathway (1) will be a major reaction pathway for the addition reaction between carbene and glycine.

\section{CONCLUSIONS}

The mechanism of the addition reaction between the singlet carbene and glycine has been investigated employing the B3LYP/6-311+G* level of theory, including geometry optimization and vibrational analysis for the involved stationary points on the potential energy surface. Overall, there are two reaction pathways (1) and (2) during the addition process. Both the reactions consist of two steps. Namely, carbene and glycine first form an intermediate (IM) through a barrier-free exothermic reaction. Then this intermediate isomerizes to a product (Pro) via a transition state (TS), where both products are enantiomers actually. The barrier heights of the two reactions are 25.7 , and $51.3 \mathrm{~kJ} / \mathrm{mol}$ at the B3LYP/6-311+G* level of theory, respectively. Therefore, from the viewpoint of dynamics, the pathway (1) will be a major reaction path for the addition reaction between carbene and glycine.

\section{ACKNOWLEDGMENTS}

This work is supported by NSFC $(21003082,31070046)$, the Project of Shandong Province Higher Educational Science and Technology Program (J09LB01, J09LB17), and the Foundation for Outstanding Young Scientist in Shandong Province (BS2009HZ014, BS2010NJ009). We are also grateful to the reviewers for their insightful suggestions to improve the presentation of the results.

\section{REFERENCES}

1.- W. Kirmse, Carbene Chemistry, Academic Press, 1964, New York.

2 .- M. Garcia, C. D. Campo, E. F. Llama, Tetrahedron Lett. 49, 8433, (1993).

3.- M. Garcia, C. D. Campo, E. F. Llama, J. Chem. Soc., Perkin Trans. I 1771, (1995).

4.- R. R. Kostikov, A. F. Khlebnikov, V. Y. Bespalov, J. Phys. Org. Chem. 6, 83, (1993).

5.- M. Mitani, Y. Kobanashi, K. Koyama, J. Chem. Soc., Perkin Trans. I 653, (1995).

6 .- X. H. Lu, W. R. Wu, H. B. Yu, et al. Chin Sci Bull 50, 2281, (2005).

7.- L. Peng, Q. S. Li, W. H. Fang, et al. Chem. Phys. Lett. 382, 126, (2003).

8.- P. J. Stang, J. Am. Chem. Res. 15, 348, (1982).

9.- B. Jeannette, R. Cyril, M. Lavinia, B. Mikael, Appl. Microbiol. Biotechnol. $81,1,(2008)$.

10.- M. V. Baker, P. J. Barnard, S. J. Berners-Price, et al. Dalton 3708, (2006).

11.- Z. Agnes, U. Sushen, N. Ferenc, et al. Catal. Lett. 115, 163, (2007).

12.- X. H. Lu, Y. X. Wang, J. Phys. Chem. A 107, 7885, (2003).

13.- X. H. Lu, Y. X. Wang, J. Mole. Struct. (THEOCHEM) 686, 207, (2004).

14.- Y. Wang, H. Li, Acta Phys-Chim. Sin. 20, 1339, (2004).

15.- Y. Apeloig, M. Karni, P. J. Stang, et al. J. Am. Chem. Soc. 105, 4781, (1983).

16.- D. P. Fox, P. J. Stang, Y. Apeloig, M. Karni, J. Am. Chem. Soc. 108, 750, (1986).

17.- C. R. Wolf, D. Mansuy, W. Nastainczyk, et al. Mol. Pharmacol. 13, 698, (1977).

18.- B. A. Chabner, P. C. Amrein, B. Druker, et al. The Pharmacological Basis of Therapeutics. 2006, McGraw-Hill, New York.

19.- I. Takuya, H. Yusuke, O. Masahiro, K. Shosuke, Pharm. Res. 25, 598, (2008).

20.- P. Hohenberg, W. Kohn, Phys. Rev. B 136, 864, (1964).

21.- A. D. Becke, J. Chem. Phys. 98, 5648, (1993).

22.- J. Satgi, Pure Appl. Chem. 56, 137, (1984).

23.- C. Lee, W. Yang, R. G. Parr, Phys. Rev. B 37, 785, (1988).

24.- R. F. Bader, Atoms in molecules: a quantum theory, 1990, Oxford University, New York.

25.- M. J. Frisch, et al. Gaussian 98, Gaussian Inc, Pittsburgh, PA, 1998.

26.- A. G. Császár, J. Am. Chem. Soc. 114, 9568, (1992). 